TITLE:

\title{
Agglomeration process of dry ice particles produced by expanding liquid carbon dioxide
}

$\operatorname{AUTHOR}(S):$

Liu, Yi-Hung; Maruyama, Hiroyuki; Matsusaka, Shuji

\section{CITATION:}

Liu, Yi-Hung ... [et al]. Agglomeration process of dry ice particles produced by expanding liquid carbon dioxide. Advanced Powder Technology 2010, 21(6): 652-657

\section{ISSUE DATE:}

2010-11

URL:

http://hdl.handle.net/2433/194294

\section{RIGHT:}

(c) 2010 The Society of Powder Technology Japan. Published by Elsevier B.V.; NOTICE: this is the author's version of a work that was accepted for publication in Advanced Powder Technology. Changes resulting from the publishing process, such as peer review, editing, corrections, structural formatting, and other quality control mechanisms may not be reflected in this document. Changes may have been made to this work since it was submitted for publication. A definitive version was subsequently published in Advanced Powder Technology, 21(6) 652-657, 2010,

doi:10.1016/J.apt.2010.07.009; This is not the published version. Please cite only the published version.; この論文は出版 社版でありません。引用の際には出版社版をご確認ざ利用ください。 


\title{
Agglomeration process of dry ice particles produced by expanding liquid carbon dioxide
}

\author{
Yi-Hung Liu, Hiroyuki Maruyama, Shuji Matsusaka* \\ Department of Chemical Engineering, Kyoto University, Kyoto 615-8510, Japan
}

\begin{abstract}
Formation of dry ice particles and their agglomeration process have been studied experimentally. The dry ice particles were produced by expanding liquid carbon dioxide at room temperature and pressure, and then introduced into an additional tube acting as an agglomeration chamber. In the experiments, the temperatures of the jet flow and the tube wall were measured by thermocouples, and dry ice particles in the jet flow were observed by a high speed camera with a zoom lens. It was found that two stages of temperature reduction occurred in the jet flow, corresponding to the agglomeration process. It was also found that the particle size of the agglomerates increased and the particle velocity decreased with increasing tube diameter. The agglomeration process of dry ice particles can be explained by the particle deposition and reentrainment, i.e. dry ice particles of several micrometers are deposited on the tube wall and form a deposition layer; then, agglomerates are reentrained from the layer into the jet flow.
\end{abstract}

Keywords: Dry ice; Jet flow; Agglomeration; Particle deposition; Reentrainment

* Corresponding author. E-mail addresses: matsu@cheme.kyoto-u.ac.jp (S. Matsusaka). 


\section{Introduction}

Dry ice jet is widely used as an industrial technique, which can not only be applied to surface cleaning for semiconductor devices, automotive molds, food processing equipments, etc. but also to food refrigeration and pharmaceutical granulation. This is because the system has the specific feature of low temperature gas-solids two phase flow containing sublimation particles.

The concept of dry ice jet applied to surface cleaning was first proposed in 1980s [1]. In this study, fine particles called dry ice snow was produced by expanding liquid carbon dioxide. Dry ice jet can be used for the removal of fine contaminants strongly adhering to the surfaces, due to the penetration of dry ice particles through the boundary layer. Compared with air jet where only drag force is applied for the removal of the contaminants, impact of dry ice particles substantially enhances the removal efficiency. The quantitative analysis of the cleaning effect of dry ice jet was carried out, including removal of organics as well as particulate contaminants [2-6]. The organics were found to be dissolved in liquid carbon dioxide due to the dry ice particles during impact. Other research investigated the particle removal mechanism based on a collision model $[7,8]$. The particle size of dry ice is thought to be an important factor which greatly affects the contaminant removal efficiency. Other than for cleaning applications, dry ice jet was also employed in the study of refrigeration $[9,10]$ and pharmaceutical granulation [11].

To improve the production efficiency of the dry ice particles, a thermally insulated chamber is placed after the expansion nozzle. Small dry ice particles can agglomerate in the chamber [12]. However, the formation, size and state of the dry ice particles, and the agglomeration process have not been studied in detail.

In this study, we focus on the production of the dry ice particles by expanding liquid carbon dioxide, and elucidate the mechanism of the formation of agglomerated dry ice particles.

\section{Experimental apparatus and procedures}

Dry ice particles were produced from high purity liquid carbon dioxide. A flexible thermally insulated hose, $2 \mathrm{~m}$ long and $15 \mathrm{~mm}$ in inner diameter, was connected to a 
high pressure carbon dioxide cylinder and an expansion nozzle was installed at the end of the hose, as shown in Fig. 1. In order to change the conditions of the expanded flow, a glass tube was placed at the outlet of the expansion nozzle. The primary pressure of the carbon dioxide was measured at the entrance of the expansion nozzle.

Fig. 2 shows the details of the test section, which consists of the expansion nozzle and the glass tube. The expansion nozzle has an inner diameter of $0.2 \mathrm{~mm}$ and a length of $6 \mathrm{~mm}$, while the glass tube was 2, 4, or $6 \mathrm{~mm}$ in inner diameter and $50 \mathrm{~mm}$ in length $(L)$, and was installed onto the outlet of the nozzle. The temperatures of the dry ice jet ejecting from the expansion nozzle and of the glass tube wall were measured by a K-type thermocouple connected to a temperature recorder (NR-1000, KEYENCE Corp.). A high speed camera (Fastcam-Max, Photron Ltd.) with a zoom lens was used to observe the state of agglomerated dry ice particles in the jet flow.

To investigate the formation of a deposition layer of dry ice particles, a glass plate instead of the glass tube was placed at the outlet of the expansion nozzle. The structures of the dry ice particles deposited on the plate were observed by an optical microscope (DS-3040L, Olympus Corp.). All the experiments were conducted under room temperature and pressure $\left(25 \pm 2{ }^{\circ} \mathrm{C} ; 1 \mathrm{~atm}\right)$.

\section{Results and discussion}

\subsection{Effect of temperature of jet flow on producing dry ice particles}

\subsubsection{Experiment using expansion nozzle}

Carbon dioxide was expanded from the nozzle at a primary pressure of $6.5 \mathrm{MPa}$ to atmospheric pressure. The expanded gas flow was cooled by rapid expansion. Fig. 3 shows the temperature measured at the center of the expanded flow along the flow axis. The measurement position $x$ is the distance from the nozzle outlet. The temperature measured at $x=1 \mathrm{~mm}$ was about $-80{ }^{\circ} \mathrm{C}$; however, it increased to $-10^{\circ} \mathrm{C}$ at $x=50 \mathrm{~mm}$ and closed to room temperature at $x>100 \mathrm{~mm}$. The temperature of the flow increased sharply after ejecting from the expansion nozzle. According to a phase diagram of carbon dioxide, dry ice can be formed at $-78.5^{\circ} \mathrm{C}$ and $1 \mathrm{~atm}$, which indicates that most 
of dry ice produced from the expansion nozzle sublimated to the atmosphere due to the temperature increase. Consequently, dry ice particles were not observed visually.

\subsubsection{Experiment using expansion nozzle with glass tube}

In order to avoid the direct contact of the expanded flow and the surrounding air, a glass tube was installed at the outlet of the nozzle, and an experiment was carried out under the same conditions as above. The dry ice particles were observed visually in the jet flow from the glass tube. Fig. 4 shows the temperature variation of the outer tube wall as a function of time elapsed. The room temperature was $25^{\circ} \mathrm{C}$. For $x=5 \mathrm{~mm}$ (Fig. 4a), the temperature decreased and approached about $-30{ }^{\circ} \mathrm{C}$ after $300 \mathrm{~s}$ had elapsed. As for $x=48 \mathrm{~mm}$ (Fig. 4b), the decrease of the temperature was relatively slow, and the stable temperature after $300 \mathrm{~s}$ was slightly higher than that for $x=5 \mathrm{~mm}$, due to the heat transfer between the jet flow and the surrounding air through the tube wall. It is worth noting that the temperature at $x=48 \mathrm{~mm}$ was still kept at sub-zero temperature, i.e. the thermal insulation of the tube wall was effective; thus the sublimation of the dry ice particles produced by expanding liquid carbon dioxide was reduced. As a result, the dry ice particles were observed visually in the jet flow from the glass tube. In this experiment, glass tubes with different diameters were also used. Although there were small differences in the results, the temperature variations were almost the same as each other.

Next, the time course of the temperature in the jet flow was measured. As shown in Fig. 5, the temperature decreased from room temperature as time elapsed and approached a stable temperature of $-55 \pm 5^{\circ} \mathrm{C}$, and then began to decrease further. The secondary stable temperature was $-65{ }^{\circ} \mathrm{C}$, i.e. there were two stages of temperature decrease in the jet flow. After the secondary temperature decrease, dry ice particles were observed visually in the jet flow from the glass tube. Thus, the secondary temperature decrease is very important in the occurrence of this phenomenon. For larger size glass tubes, the temperature was higher in the first stage, and the difference of the stable temperature between $2 \mathrm{~mm}$ and $6 \mathrm{~mm}$ in inner diameter was about $10{ }^{\circ} \mathrm{C}$. Since larger glass tubes have a larger surface area; thus, the heat transfer through the tube wall is enhanced. Consequently, the stable temperature in the first stage is higher. Further 
discussion is mentioned in Section 3.3.

\subsection{Effect of glass tube size}

Since the temperature measurement implies that the glass tube size affects the state of the jet flow, we studied the formation and behavior of the dry ice particles produced in the flow using a high speed camera with a zoom lens. Fig. 6 shows some typical images of the dry ice particles produced in the jet flow from the glass tube. Since the exposure time in these images is known (1/6000 s), particle velocity can be calculated from the length of the trajectories of the dry ice particles. The velocity of the dry ice particles decreased and the size increased with increasing tube diameter. For larger dry ice particles (Fig. 6c), the particles are more irregular in shape and seems to be agglomerated.

The particle velocity distributions are shown in Fig. 7 a. The data seem to be symmetrical distributions; as a trial, they are plotted on a normal graph. As shown in Fig. 7 b. each distribution is in a line; thus they are expressed as normal distributions. The median values for $D_{\mathrm{i}}=2,4$, and $6 \mathrm{~mm}$ are 13.8, 6.9, and $3.4 \mathrm{~m} / \mathrm{s}$, respectively. The standard deviations for each tube diameter (from small to large) are 1.8, 1.7, and $1.4 \mathrm{~m} / \mathrm{s}$, and the coefficients of variation (standard deviation/mean value) are $0.13,0.25$, and 0.41 , respectively.

If the mass flow rate of the carbon dioxide is constant, the flow velocity ratio may be proportional to the inverse ratio of the cross section area of the glass tube. As the ratio of inner tube diameter is $1: 2: 3$, the flow velocity ratio is 9:2.25:1. The velocity ratio obtained experimentally was 9:4.5:2.2. Although the experimental results agree roughly with the theoretical values, the experimental results for larger tube diameter are relatively greater. This is probably because dry ice particles highly sublimated due to the heat transfer, and the amount of gas increased.

The particle size and shape is difficult to be determined from the image of the side view since the particles are moving with high velocities and there are many particles out of focus. The images should be taken from behind a glass plate set in the front of the jet flow. The flowing dry ice particles are trapped on the surface of the glass plate for a very short period and thus the particles in the focus depth can be easily observed. 
Fig. 8 shows the images of dry ice particles taken from behind this glass plate. The size and shape was able to be estimated from the images. The size of dry ice particles increased with the tube diameter, and many agglomerates in Fig. 8c were several hundred micron meters in equivalent circle diameter based on projected area. The visible particles were agglomerated and the shape was irregular. The large agglomerates seem to have a loosely packed structure.

Fig. 9 shows the particle size distribution of the dry ice particles for different glass tube sizes. The data shows unsymmetrical distributions, which means a small amount of larger agglomerates were generated. The data are plotted on a lognormal graph, as shown in Fig. 9b. Although they are not necessarily expressed as lognormal distributions, the geometric mean diameters, $D_{\text {ag50, }}$ and apparent geometric standard deviations, $\sigma_{\mathrm{ag}}\left(=\left(D_{\mathrm{ag} 84.1} / D_{\mathrm{ag} 15.9}\right)^{0.5}\right)$, can be determined, i.e. for $D_{\mathrm{i}}=2$, 4, and $6 \mathrm{~mm}$, $D_{\text {ag50 }}=55,85$, and $183 \mu \mathrm{m}$, and $\sigma_{\mathrm{ag}}=1.2,1.5$, and $1.5 \mu \mathrm{m}$, respectively.

\subsection{Interparticle collisions on the agglomeration of dry ice particles in the glass tube}

Dry ice particles can collide with each other in the flow, and generate agglomerated particles, which depends on the experimental conditions such as residence time of the dry ice particles in the glass tube. The residence time can be calculated by dividing the tube length by each average particle velocity (see Fig. 7). The residence time for $D_{\mathrm{i}}=2$, 4, and $6 \mathrm{~mm}$ are, respectively, 3.6, 7.2, and $14.7 \mathrm{~ms}$. Since the average particle size ranges from 55 to $183 \mu \mathrm{m}$ (see Fig. 9), a large number of collisions of primary particles are needed to generate such large agglomerates. However, the particle collisions can hardly be achieved in the limited residence time; thus, there may be another important factor in the agglomeration process. The glass tube has great influence on the particle agglomeration, and the tube wall may affect the agglomeration process. Further discussion is presented in the next section.

3.4. Effect of particle deposition and reentrainment on the agglomeration of dry ice particles in the glass tube

In general, fine particles in gas-solids pipe flow deposit on a wall surface and form 
a particle layer. The drag force acting on the layer increases with the mass of deposited particles and agglomerated particles are reentrained readily from the layer [13]. Also, the collision of the flowing particles to the deposition layer enhances the reentrainment. Finally, the particle deposition and the reentrainment become in equilibrium [14]. To investigate the formation of the deposition layer of dry ice particles, another experiment was carried out. A glass plate was placed in parallel to the axis of the expanded flow to observe the formation of the deposition layer from the side. The distance $d$ from the plate surface and the expanded flow axis was varied to simulate the flow in the glass tube of different diameter. A high speed camera with a zoom lens was used to observe the formation of the deposition layer. The dry ice particles ejected from the nozzle began to deposit on the glass plate when the surface temperature was sufficiently low. The dry ice deposition layer gradually formed and the thickness increased as time elapsed.

Fig. 10 shows the deposition layer of the dry ice particles formed on the glass plate placed at different distances. For $d=1 \mathrm{~mm}$, the dry ice particle deposition layer was densely packed and the surface was smooth. The thickness of the layer increased with increasing horizontal distance from the nozzle outlet, as shown in Fig. 10 a. Thicker deposition layers were also observed for $d=2$ and $3 \mathrm{~mm}$ (Fig. $10 \mathrm{~b}$ and c). Furthermore, it was found that the deposition layer in Fig. 10 c was formed away from the nozzle outlet $(x=25 \mathrm{~mm})$ and had a loosely packed structure. Since the interaction between particles is small in the loosely packed structure, agglomerated particles can be easily reentrained from the deposition layer even though the flow velocity is relatively low. The size of the agglomerated particles increases as the packing density of the deposition layer decreases. Therefore, the agglomerated dry ice particles shown in Figs. 6 and 8 are considered to be caused by the particle deposition and reentrainment.

Next, we explain the details of the temperature variation of the jet flow from the tube shown in Fig. 5 by the particle deposition and reentrainment. When the wall temperature is lowered by the expanded flow, the dry ice particles ejected from the nozzle begin to deposit on the tube wall. The dry ice deposition layer is gradually formed. During this phenomenon, the temperature of the jet flow from the glass tube decreases and approaches a stable value. When the agglomerated particles begin to reentrain from the deposition layer, the thermal equilibrium in this system is not 
maintained and the temperature of the flow decreases again. Once the particle deposition and reentrainment is in equilibrium, the temperature of the flow is stable again.

Since the deposition layer is composed of dry ice particles, it is of great interest to investigate the structure of the deposition layer. Fig. 11 shows the optical microphotographs of the dry ice particle deposition layer formed on the glass plate placed at $d=1$ and $3 \mathrm{~mm}$. The deposition layer was formed in a stripe shape and orientated toward the flow direction. Many dry ice particles of several micrometers in diameter were observed in the deposition layer. It was found that the sizes of the dry ice particles in the deposition layer formed under different conditions were almost the same, as shown in Fig. 11. The fine particles are thought to be the primary particles of dry ice produced by the expanding flow. Therefore, the agglomerated particles reentrained will also consist of the fine dry ice particles.

In the present work, the agglomeration process of dry ice particles was discussed on the basis of the experimental facts. Quantitative analysis and modeling can be taken up in future.

\section{Conclusions}

The agglomeration process of dry ice particles was studied by measuring the temperature of the jet flow and the tube wall and observing the phenomena, and the mechanism for dry ice agglomeration was discussed. The following conclusions were drawn:

(1) The dry ice jet is able to be kept at a lower temperature by adding a glass tube to the outlet of the expansion nozzle. The temperature of dry ice jet decreases and approaches a stable temperature in the early stage; then moves to a second stable temperature. The dry ice particles agglomerated are observed visually after the second reduction of the temperature.

(2) The particle velocity and size were analyzed through the images taken by the high speed camera. Tube size has great influence on the particle size and shape as well as velocity. Since the residence time is limited, a large number of collisions of primary particles can hardly be achieved; thus the agglomerates observed cannot be 
generated by the interparticle collisions in the flow.

(3) After the dry ice particles produced deposit on the wall and form a particle layer, agglomerates are reentrained from the layer into the jet flow. As a result, dry ice particles can be observed visually in the jet flow.

(4) A microscopic observation shows that the deposition layer consists of fine dry ice particles of several micrometers. The agglomerated particles reentrained from the deposition layer will also consist of the fine dry ice particles.

\section{Acknowledgement}

This research was supported in part by the Global COE Program "International Center for Integrated Research and Advanced Education in Materials Science" (No. B-09) of the Ministry of Education, Culture, Sports, Science and Technology (MEXT) of Japan, administrated by the Japan Society for the Promotion of Science.

\section{References}

[1] S. A. Hoenig, Cleaning surfaces with dry ice, Compressed Air Magazine, 91 (8) (1986) 22-25.

[2] R. Sherman, W. Whitlock, The removal of hydrocarbons and silicone grease stains from silicon wafers, J. Vac. Sci. Technol. B 8 (1990) 563-567.

[3] L. Layden, D. Wadlow, High velocity carbon dioxide snow for cleaning vacuum system surfaces, J. Vac. Sci. Technol. A 8 (1990) 3881-3883.

[4] R. Sherman, J. Grob, W. Whitlock, Dry surface cleaning using $\mathrm{CO}_{2}$ snow, J. Vac. Sci. Technol. B 9 (1991) 1970-1977.

[5] R. Sherman, D. Hirt, R. Vane, Surface cleaning with the carbon dioxide snow jet, J. Vac. Sci. Technol. A 12 (1994) 1876-1881.

[6] M.M. Hills, Carbon dioxide jet spray cleaning of molecular contaminants, J. Vac. Sci. Technol. A 13 (1995) 30-34.

[7] C. Toscano, G. Ahmadi, Particle removal mechanisms in cryogenic surface cleaning, J. Adhesion, 79 (2003) 175-201.

[8] S. Banerjee, A. Campbell, Principles and mechanisms of sub-micrometer particle removal by $\mathrm{CO}_{2}$ cryogenic technique, J. Adhesion Sci. Technol., 19 (2005) 739-751. 
[9] H. Yamaguchi, X. R. Zhang, K. Fujima, Basic study on new cryogenic refrigeration using $\mathrm{CO}_{2}$ solid-gas two phase flow, Int. J. Refrigeration, 31 (2008) 404-410.

[10] H. Yamaguchi, X. R. Zhang, A novel $\mathrm{CO}_{2}$ refrigeration system achieved by $\mathrm{CO}_{2}$ solid-gas two-phase fluid and its basic study on system performance, Int. J. Refrigeration, 32 (2009) 1683-1693.

[11] R. Sonoda, Y. Hara, T. Iwasaki, S. Watano, Improvement of dissolution property of poorly water-soluble drug by supercritical freeze granulation, Chem. Pharm. Bull., 57 (2009)1040-1044.

[12] E. A. Swain, S. R. Carter, S. A. Hoenig, Carbon dioxide snow agglomeration and acceleration, U.S. Patent (1992) 5125979 .

[13] I. Adhiwidjaja, S. Matsusaka, H. Tanaka, H. Masuda, Simultaneous phenomenon of particle deposition and reentrainment: effects of surface roughness on deposition layer of striped pattern, Aerosol Sci. and Technol., 33 (2000) 323-333.

[14] W. Theerachaisupakij, S. Matsusaka, Y. Akashi, H. Masuda, Reentrainment of deposited particles by drag and aerosol collision, J. Aerosol Sci., 34 (2003) 261-274. 


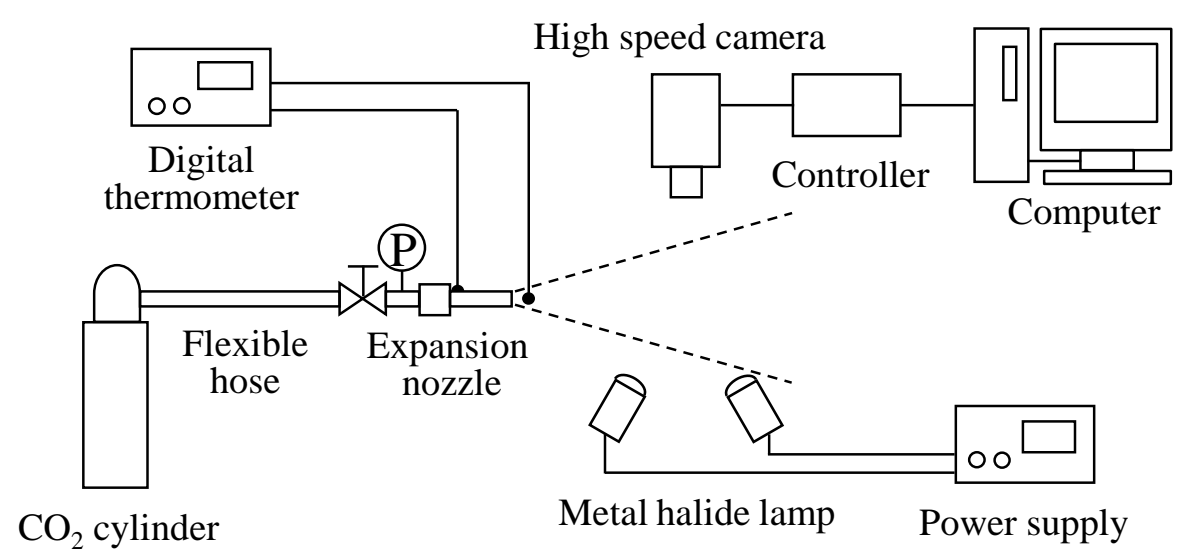

Fig. 1. Schematic diagram of experimental apparatus. 


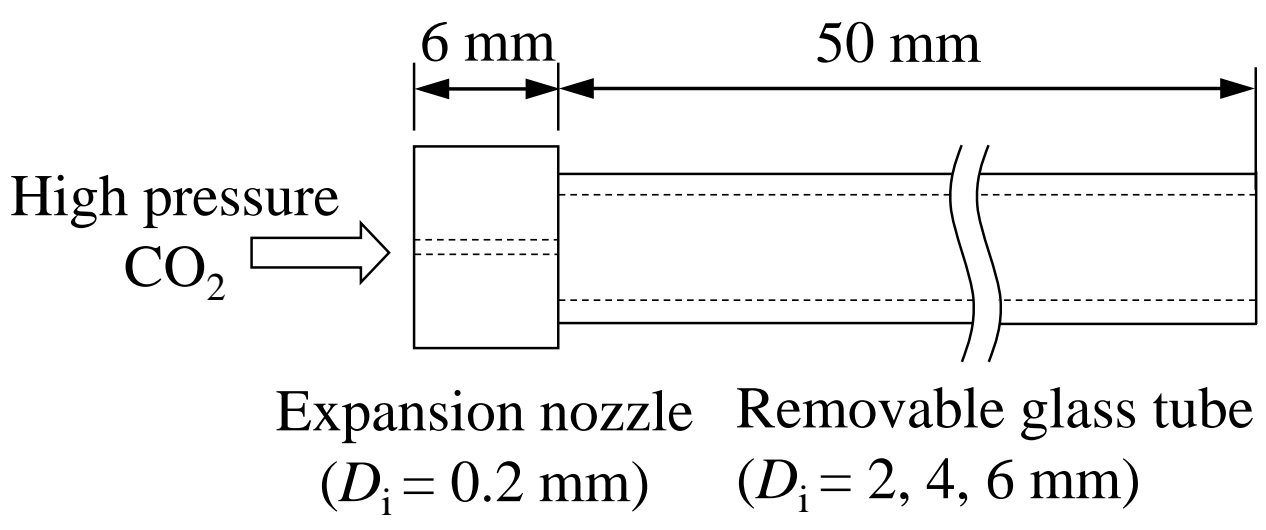

Fig. 2. Test section. 




Fig. 3. Temperature variation with distance from expansion nozzle. 

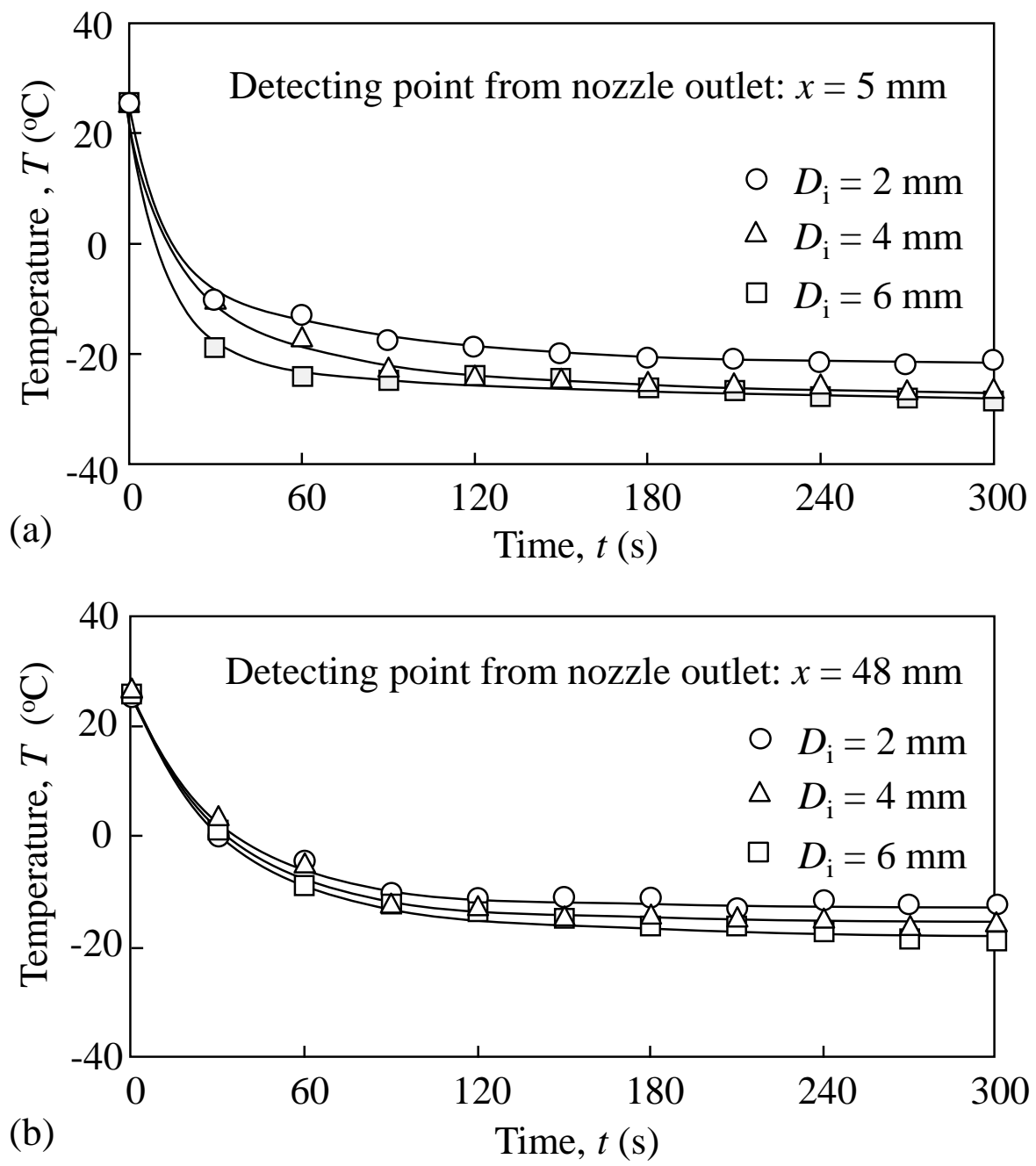

Fig. 4. Temperature variation of outer tube wall. 


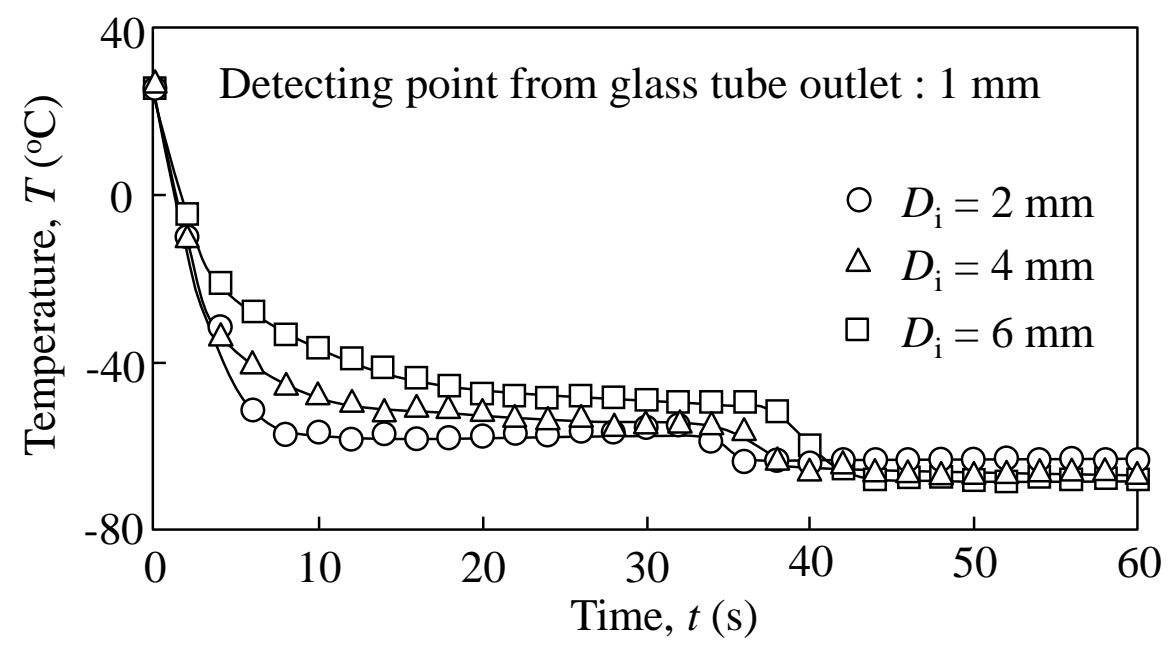

Fig. 5. Temperature variation of dry ice jet. 


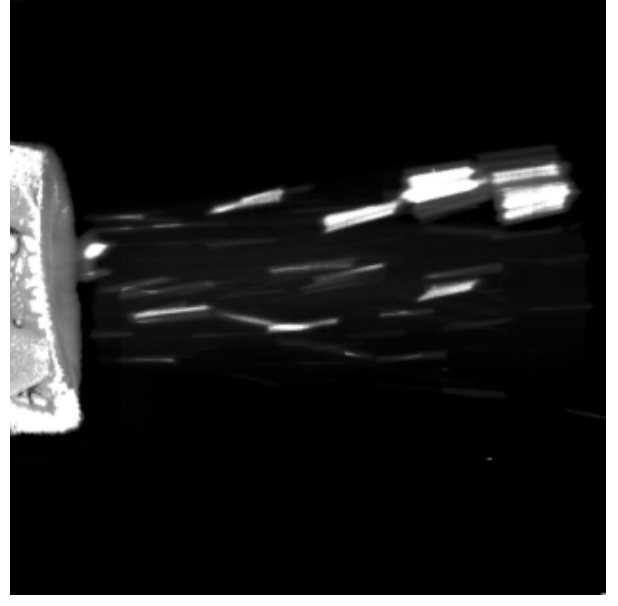

(a) $D_{\mathrm{i}}=2 \mathrm{~mm}$

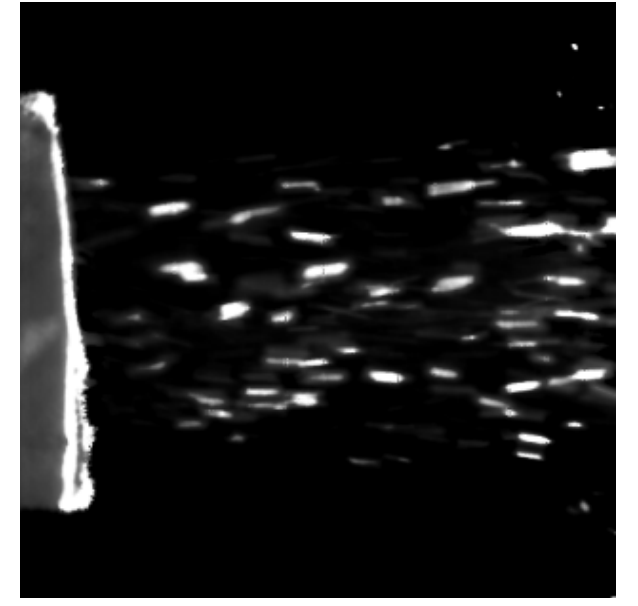

(b) $D_{\mathrm{i}}=4 \mathrm{~mm}$

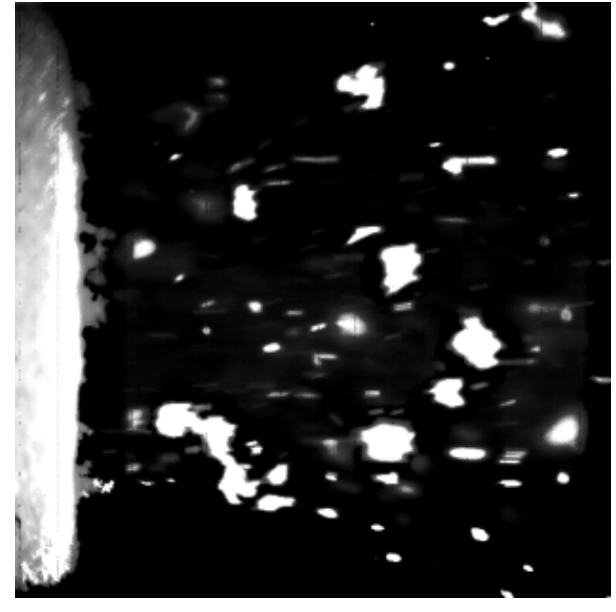

(c) $D_{\mathrm{i}}=6 \mathrm{~mm}$

Fig. 6. Dry ice particles flowing out of the tube ( $L: 50 \mathrm{~mm}$, exposure time: 1/6000 s). 

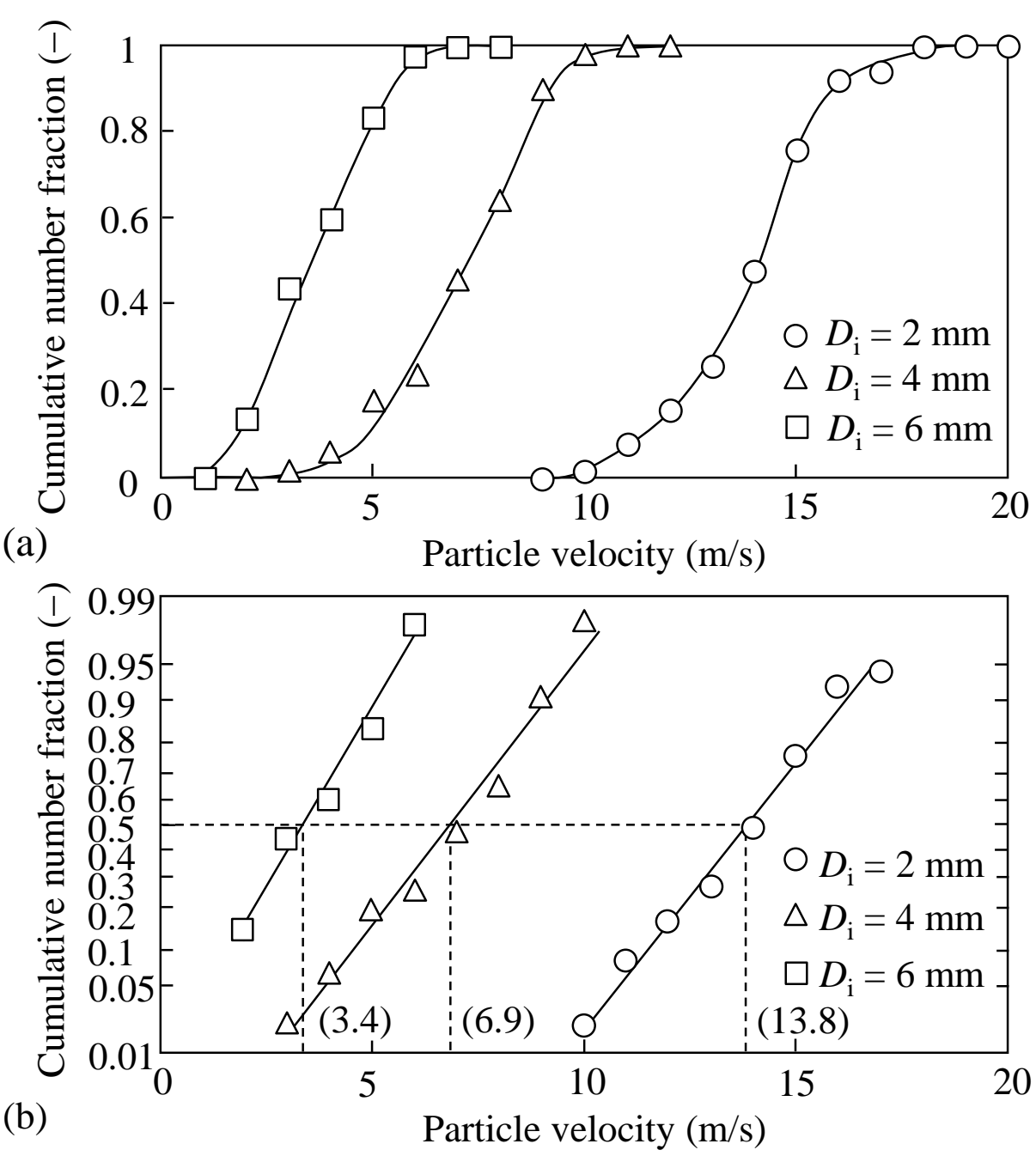

Fig. 7. Particle velocity distribution: (a) plain graph; (b) normal graph. 

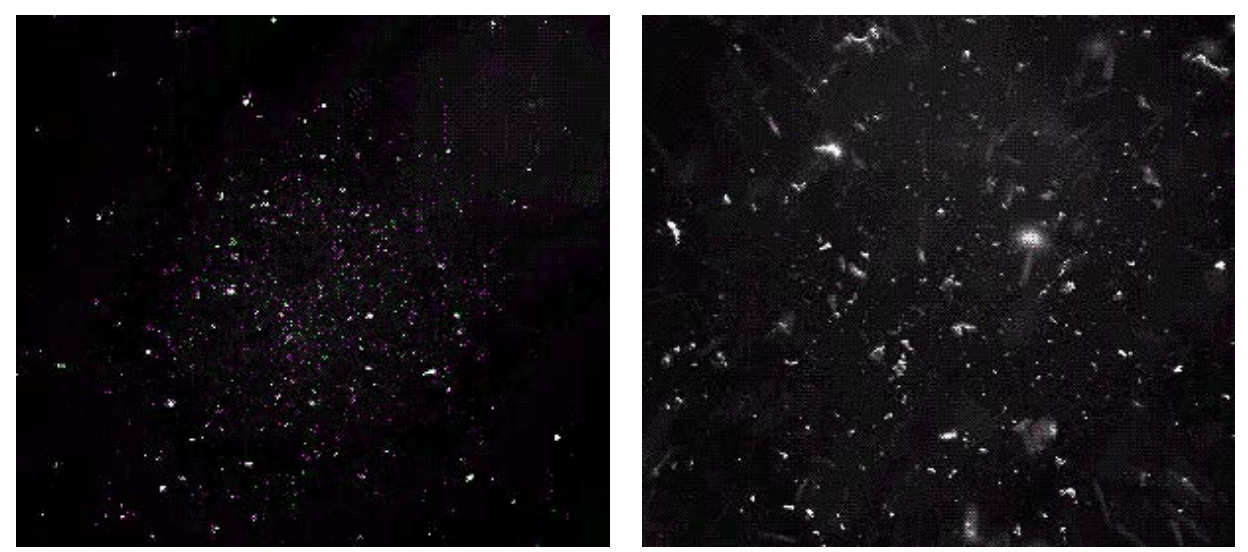

(a) $D_{\mathrm{i}}=2 \mathrm{~mm}$

(b) $D_{\mathrm{i}}=4 \mathrm{~mm}$

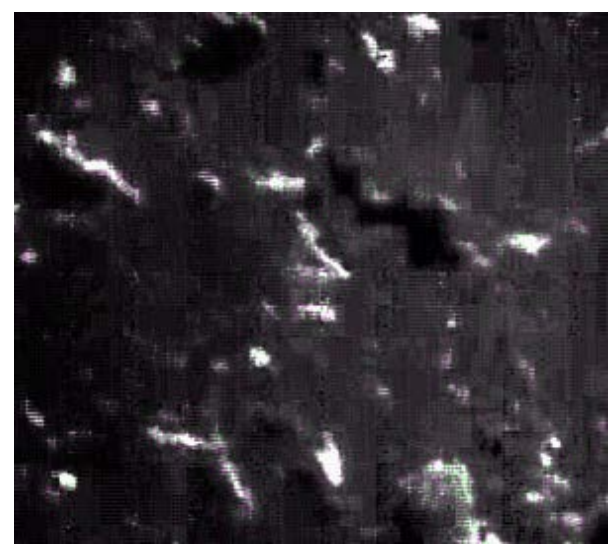

(c) $D_{\mathrm{i}}=6 \mathrm{~mm}$

$\stackrel{1 \mathrm{~mm}}{\longmapsto}$

Fig. 8. Effect of tube diameter on agglomerate formation (view from behind, $L$ : $50 \mathrm{~mm}$, exposure time: 1/6000 s). 

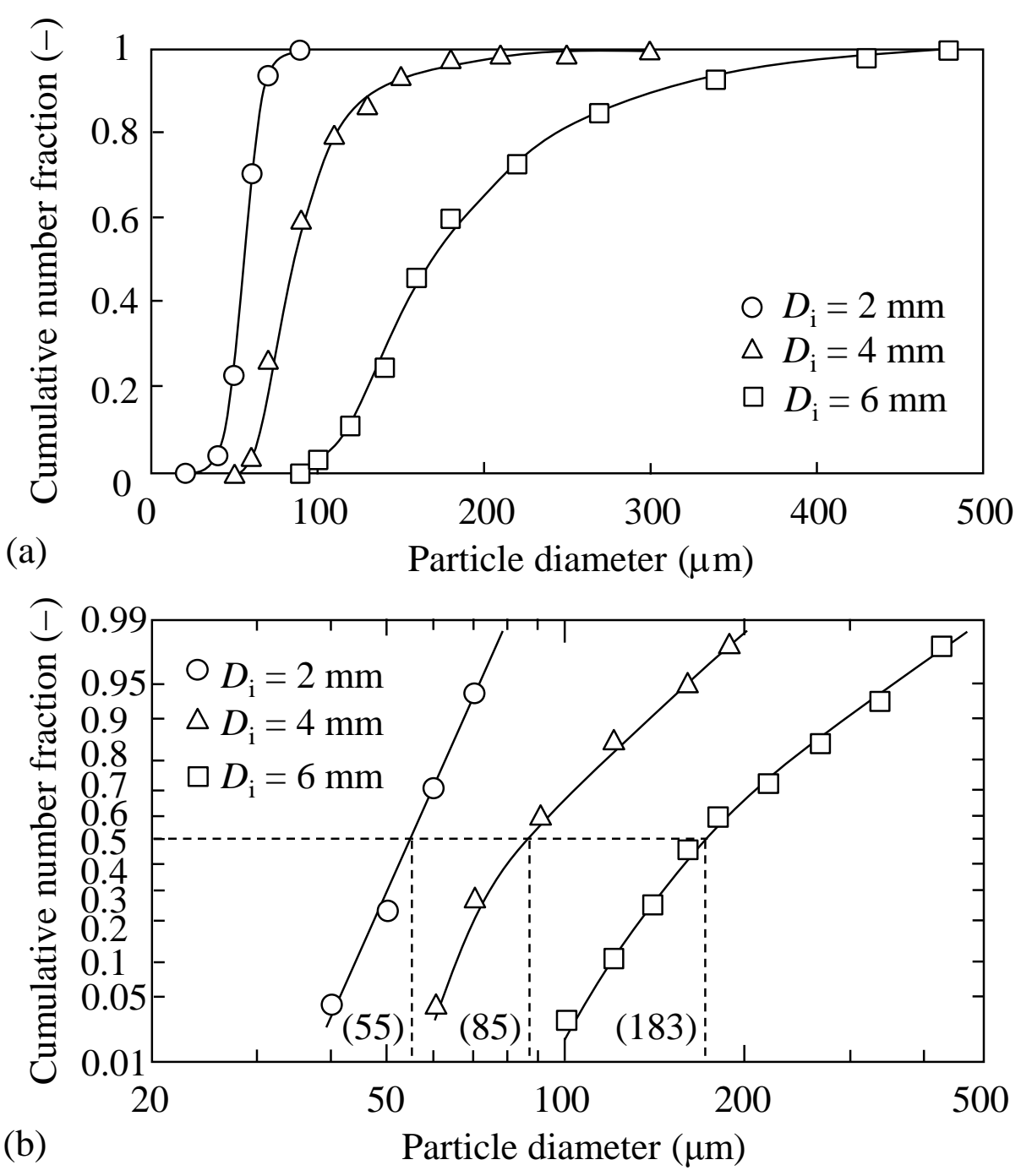

Fig. 9. Cumulative particle size distribution : (a) plain graph; (b) lognormal graph. 


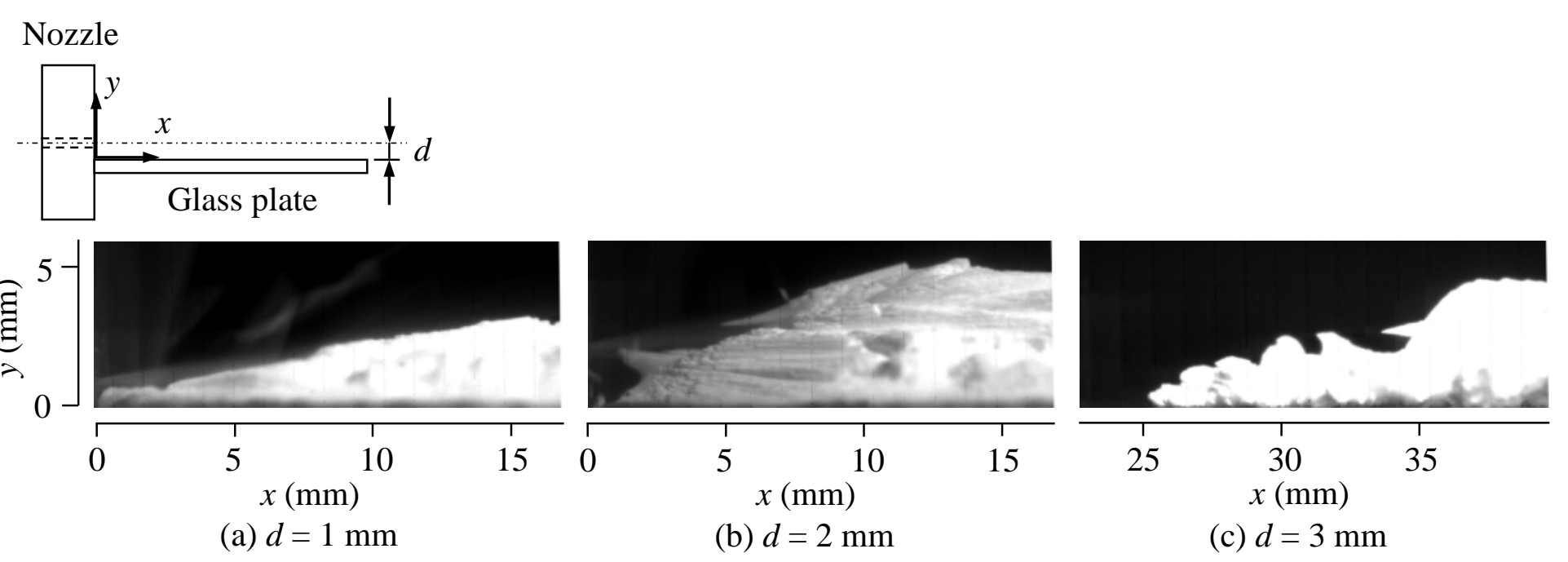

Fig. 10. Deposition layer of dry ice particles formed on glass plate. (exposure time: 1/6000 s). 
Flow direction

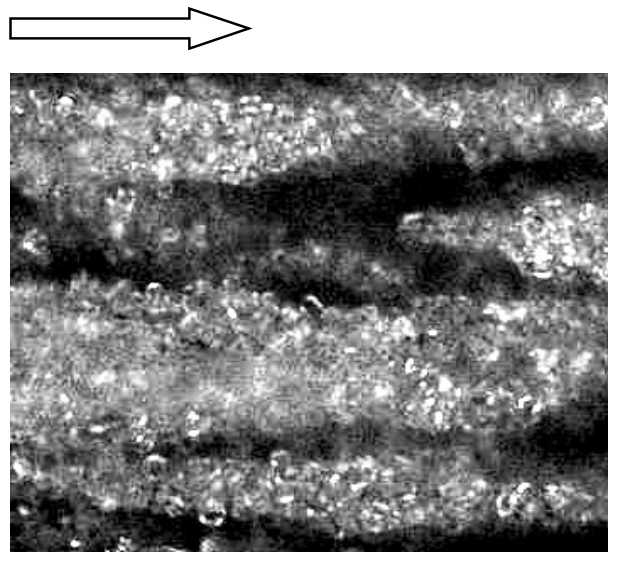

(a) $d=1 \mathrm{~mm}$ $x=17 \mathrm{~mm}$

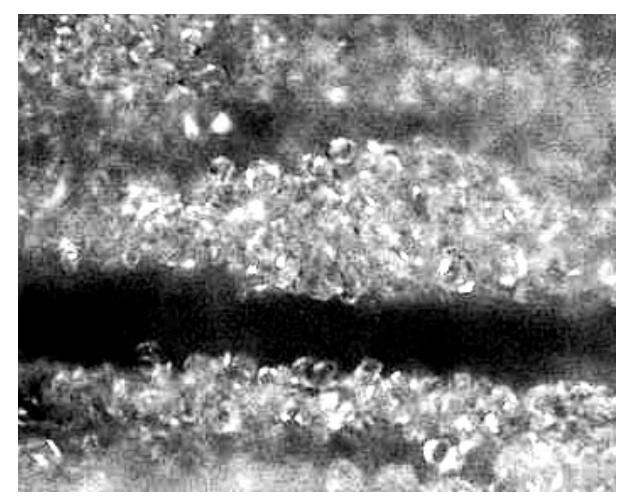

(b) $d=3 \mathrm{~mm}$ $x=35 \mathrm{~mm}$

Fig. 11. Deposition layer of dry ice particles observed through an optical microscope ( $d$ is described in Fig. 10). 